\title{
تصميم منهج تعليم اللغة العربية للأطفال على أساس التربية السلوكية بروضة "التمام" بندارلامفونج
}

\author{
Intan Muflihah \\ e-mail: intanmuflihah@gmail.com
}

UIN Raden Intan Lampung

Jln.Endro Suratmin Sukarame Bandar Lampung

ملخص :إن التربية للأطفال هي مرحلة التربية قبل التربية الأساسية (نقوله بالمدرسة الابتدائية)، وهي العملية المواجهة للأطفال بإحضار المثير التربوي لمساعدة تنمية الباطني والظاهري نهو العمر · إلى 7 سنوات حتى يكون الطفل مستعدا لاستمرار مرحلة تربيته. تقع في مرحلة الطفولة المبكرة بداية

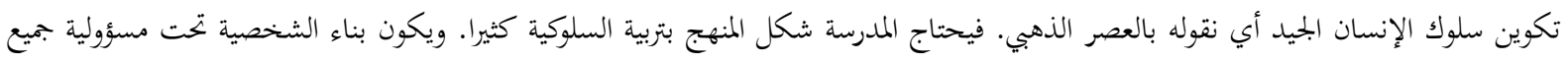
جوانب الحياة، البيت والمدرسة هما المسؤلين والعاملين المؤثرة الكبيرة في هذه المرحلة. قام هذا البحث في تطوير منهج تعليم اللغة العربية للأطفال على أساس التربية السلوكية بروضة الأطفال "التمام" بندار لامفونج. فالأسئلة من هذا البحث هي: (1) كيف يتم تصميم منهج تعليم اللغة العربية على لى

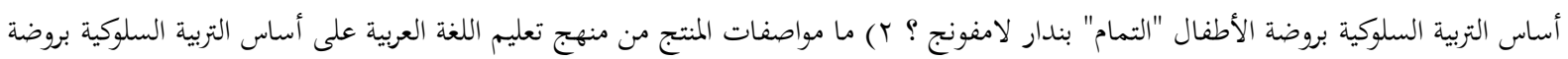
الأطفال "التمام" بندار لامفونج ؟ ؟) المنتج من ما مدى صلاحية منهج تعليم اللغة العربية على أساس التربية السلوكية بروضة الأطفال "التمام" بندار لامفونج ؟ تستخدم الباحثة في هذا البحث منهج البحث التطويري (R \& D وهي طريقة البحث المستخدمة للحصول على نتاج معين وبتربية فعالة. وليحصل على الإنتاج الجيد، تستخدم الباحثة تحليل الحاجات قبل عملية التصميم. وتصمم الباحثة منهج تعليم اللغة العربية ثم تطوره في بحال التربية لترقية فعالية تعلم اللغة العربية في روضة الأطفال. والنتائج التى ستطورها الباحثة من تصميم هذا المنهج يشمل على عملية الطلبة في روضة الأطفال ويشتمل أيضا على عناصر المنهج الأربعة، هي الأهداف التعليمية، والمختوى، وطرائق التدريس، والتقويم. تعرض الباحثة النتائج المستفادة: ( )

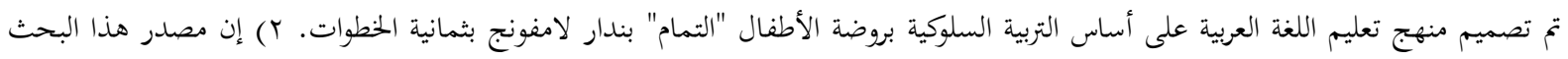

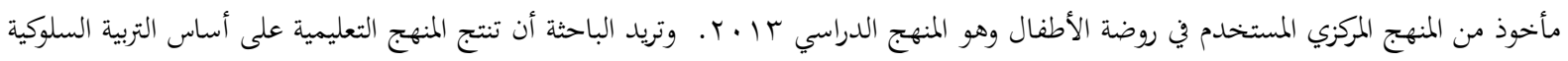

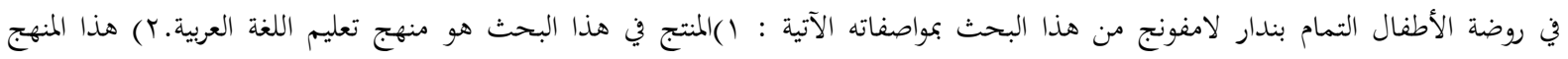
مكتوب في عدد من الصفحات الورقية. ب) يتكون هذا المنهج المكتوب من : الإطار العام، ذاتية روضة الأطفال، التقويم الدراسي، الأهداف العامة والأهداف الخاصة في تعليم اللغة العربية في روضة الأطفال التمام، الأنشطة التعليمية في روضة الأطفال التمام، طرق التعليم المستخدمة، المقرر الدراسي

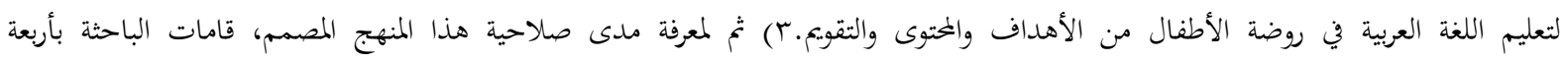
الخطوات.ومن هذه الخطوات، تخلص الباحثة بنتيجتين :يتضح من الجحدول لنتيجة الخبراء أن مضمون المنهج المطور على أساس التربية السلوكية كله

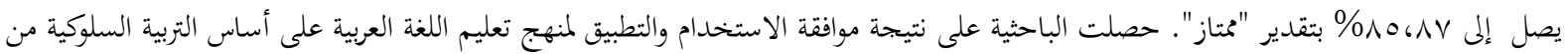

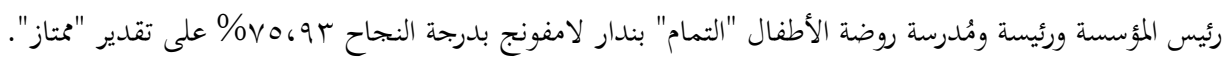


مقدمة

قد ظهر هذا العصر المؤسسات التربوية

في جميع المستوى. وليس من قليل قامت على أساس الإسلامية، كالمدارس تحت رياسة وزارة الدينية أو المدارس على اسم المدرسة الإسلامية المتكاملة تحت رياسة وزارة التربية والثقافة. وصنعت هذه المدارس المناهج وخطط الدراسية والمواد التعليمية مطابقا برؤية المدرسة ومهمتها، ولا يخرج من النظم المركزي لوزارة الدينية كانت أي وزارة التربية والثقافة. المثال في استخدام المنهح الدراسي با • ب على أساس التربية السلوكية في المدارس الحلكومية والأهلية. ينبغي على جميع المستوى التربوية من الروضة إلى الثانوية أن تستخدم لئي وتطبق المنهج الدراسي با • r. وفي الواقع أن استخدام هذا المنهج غير الشمول لبعض المدارس بإندونيسيا على الأسباب الطبيعية المتنوعة.' فصنعت بعض المدرسة المناهج وخطط الدراسية و والمواد التعليمية نفسها

\footnotetext{
'المقابلة برئيسة اتحاد مدرسي الروضة لولاية
}

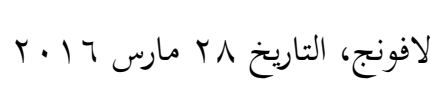$$
\text { تصميم منهج تعليم اللغة العربية للأطفال على أساس التربية السلوكية بروضة "التمام" بندارلامفونج }
$$

المنهج الدراسي r| • ب يقوم بالامتياز

والمتاجات بنظر إلى الرؤية ومهمته، على أساس التربية السلوكية. وهذه ما يحتاج في بناء الشخصية الجيدة كالمؤسسة القوية لمستقبل الأمة، خاصة على تربية الطفولة المبكرة. لماذ بمرحلة الطفولة المبكرة ؟ لأن بداية بناء الشخصة بالمدرسة تقع في هذه المرحلة. ويكون بناء الشخصة تحت مسؤولية جميع جوانب الحياة. البيت والمدرسة هما المسؤلان والعاملان المؤثرة الكبيرة. إن التربية للأطفال هي مرحلة ما قبل التربية الأساسية (نقوله بالمدرسة الابتدائية). وهي العملية المواجهة للأطفال بإحضار المثير التربوي لمساعدة تنمية الباطني والظاهري طوال العمر · إلى I سنوات، حتى يكون الطفل مستعدا لاستمرار مرحلة تربيته. وكتب في

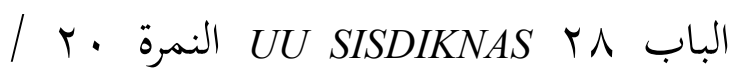
r... الأية ا أن بمموعة من العمر للحضانة هي من عمر · إلى 7 سنوات. ومعرفة عن المنهج للحضانة من العملية لتُعلم 
الأطفال بوسيلة الخبرة الظاهري من العوامل اليومية. كتب في كتاب يلاني أن تطوير المنهج للأطفال هو تطوير العملية باللعب نهو الطوفولة.

تقع في مرحلة الطفولة المبكرة بداية تكوين سلوك الإنسان الجيد أي نقوله بالعصر الذهبي. فيحتاج المدرسة شكل المنهج بتربية السلوكية كثيرا. ويكون بناء الشخصية تحت مسؤولية جميع جوانب الحياة، البيت والمدرسة هما المسؤلين والعاملين المؤثرة الكبيرة في هذه

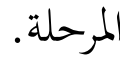

روضة "التمام" هو واحد من

مؤسسات التربوية ببندار ل لامفونج. هذه المدرسة لما الرؤية والمهمة الخاصة نحو اللغة العربية. تجعل اللغة العربية كرمز الخاصة عن هذه المدرسة، تجرب أن تكون مواصلة اللغة اليومية، ويقوم التلميذ بالخطابة العربية في حفلة التخرج السنوية. ولاكن من الآسف، لم يوجد منهج التعليم الخاص للغة العربية.

انطلقا بما سبق ذكره عن وقيعية التربوية بإندونيسيا وإجرءات تعليم اللغة العربية
بروضة "التمام"، ترى الباحثة أها من الضرورة بمكان إيجاد تصميم منهج التعليم اللغة العربية للأطفالعلى أساس التربية السلوكية بروضة "التمام" بندار لامفونج. رجاءا على تقدّم التربية هذه المدرسة وبتعل خرّيّها ذكيا ودينيا. الإطار النظري

\section{ا ـ تصميم منهج تعليم اللغة العربية}

تصميم المنهج هو العملية يتم عن

طريقه تحديد الكيفية التي سيتم بها تشييد المنهج، ويهتم تطوير المنهج بمسائل مثل: من الذي سيشترك في تشييد المنهج من معلمين

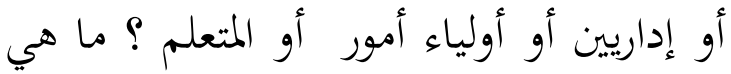
الطرائق التي ستتبع في تشييد المنهج: هل

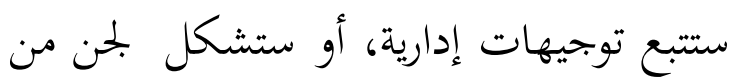
المعلمين لهذا الغرض ؟ بعات يعتمد تصميم المنهج على التفسيرات التي تقدمها النظريات للظواهر المختلفة، ولكن التصميم هنا ليس موضوعا نظريا بل هو علمي، وهم لايطور النظرية، بل يطور مبادئ عملية لتوجيه صنع القرار في المواقف العملية، وليس لإقامة علاقة بالمسائل الافتراضية بل بالأمور الإجرائية ومن القواعد التى يقاس بها 
التصميم المعقولية والقابلية للتطبيق العملي. كما أن تصميم المنهج أن يعمل على تطوير أولويات لتوجيه اختياره للمهام الواجب إبنحازها والقدرة على أدائه وتخضع هذه القرارات لتوجيه منظومة القيم ودرجة الالتزام r بها داخل المحتمع وكذلك المتعلمين أنفسهم. أ) الأطراف في تصميم المنهج

$$
\text { الدراسي }
$$

مسؤولية الخبراء التربويون في بحلس

التصحيح أو اللجنة في تخصصه، احضار التداخلات أو التقييم المتطور المنهج، البحث عن تطوير المنهج فنتيجته تكون المرجع والمعلومات الجحيد لتطوير المنهج، تخطيط الكتاب الأساسي مطابقا بالمنهج المتطور، اعطاء التدريبات إلى إلى مطور المنهج أو

'المرجع السابق،محمد محمود الخوالدة، أسس

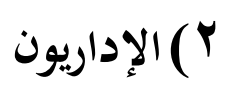$$
\text { تشزره. }
$$

بناء المناهج التربوية وتصميم الكتاب

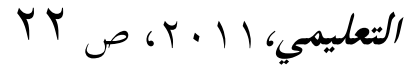

إن الإداريون له دور أكثر في تطوير المنهج الدراسي نخو نظام التربوي المركزي. ولكن عملية هذه الاسترابجية يلحق المشكلة لأن لا يطابق باحتياجات وقدرة المنطقة. وفي نظام التربوي غير المركزي، توسع دور الإداريين وتكثر لعملية المبادرة في تطوير وتخطيط وتكميل ويطابق المنهج الدراسي باحتياجات وقدرة المنطقة. فيؤثر إلى تنوع المنهج بل يصدر إلى المنهج المركزي.

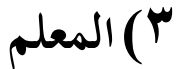

إن المعلم من أهم نقطة مركزية، وهو

كالعامل الموحد في عملية تطبيق تطوير المنهج. بجاح عملية التعليم والتعلم مطابقا كثيرا بقدرة وشخصية المعلم. دور المعلم في تطوير المنهج الدراسي يستولي على: التنظيم الإداري، تنظيم المشورة وتطوير المنهج، المعلم كمهنة التعليم، الاشتراك في عملية تطوير المنهج، ترقية بجاح النظام التعليمي، فج المنهج الدراسي، زيادة الفهم عن النفسي، تعزيز علاقة متبادلة منسجمة مع الطلاب.

Pengembangan Kurikulum, (Bandung: Rosda, 2007), hlm 230

تصميم منهج تعليم اللغة العربية للأطفال على أساس التربية السلوكية بروضة "التمام" بندارلامفونج 


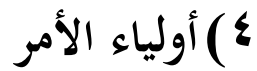

يُشترك بعض من أولياء الأمر في

عملية تطوير المنهج كأصحاب المصلحة. لهم

دور مهم في تعاون عملية المنهج في البيت.

على أولياء الأمر أن يلاحظ ويراقب عملية

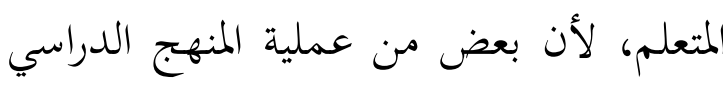
يُعمل في البيت.

$$
\text { ( ) المتعلم }
$$

في تحسين نوعية من الطلاب، يجب

المعلم ألاّ تخل عن مسؤولية المعلمين والمربيين.

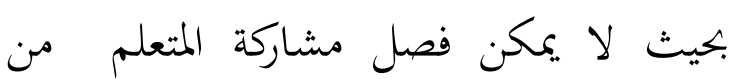

توجيه المعلمين، كإعطاء الدوافع في التعلم،

$$
\text { والتشجيع على إصدار الرأي. }
$$

\section{ب. مبادئ تصميم المنهج}

وفيما يلي بعض الأسس والمبادئ

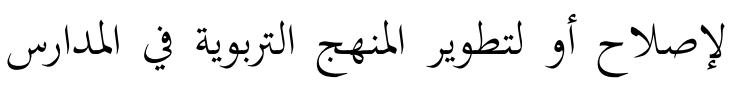

التعليمية المعاصرة:

${ }^{4}$ Ibid, hlm 231

ألمرجع السايق،محمد محمود الخوالدة، أسس بناء

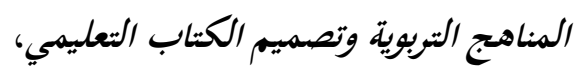

() أن تؤكد المنهج التربوية على مبدأ

التعلم الذاتي عند المتعلمين في

المدارس من أجل الاستمرار في

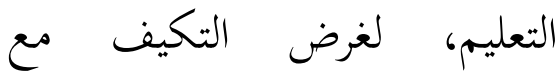

المتغيرات الثقافة المتغيرة في الواقع لمرصع

الاجتماعي والتوازن معها ليبقى

الإنسان حيا من الناحية الثقافة

وقادرا على إعطاء دوره الاجتماعي

بأحسن مستوى ممكن.

Y) أن يتم اختيار المنهج التربوية من من من

أجل تزويد المتعلمين بمعرفة فعالة،

تساعدهم على التكيف مع البحتمع

الذي ينتمون إليه.

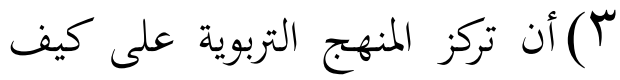

يعرف المتعلم وليس ماذا يعرف ؟

ع) أن تسهم المنهج في تشكيل عقل

المتعلمين بحيث يتمكنون من توليد

معافر جديدة من معلومات قليلة

وتوسيع قاعدة المعارف المقدمة

إليهم لغرض التكامل والاندماج

والابتعاد عن التخصص الضيق.

$r \cdot r$ ص

تصميم منهج تعليم اللغة العربية للأطفال على أساس التربية السلوكية بروضة "التمام" بندارلامفونج 
0) أن تعني المنهج التربوية بتقلديم أساسيات المعرفة وفلسفتها للمتعلمين والتطور التاريخي للفكر الإنساني وتحدياته الراهنة.

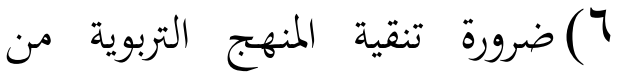
المفاهيم والأفكار الخرافية وتقديس المعرفة والتراث ومحاربة اللاعقلانية

$$
\text { في الكتب المدرسية. }
$$

( ) إدخال التكنولوجيا والمعلوماتية في بنية المنهج التربوية، بحيث تشكل جزء لا يتجزأ من بنية المنهج. ^) أن تركز المنهج التربوية على المتعلم نفسه، والاهتمام

$$
\text { الشخصي له. }
$$

9) أن تراعي المنهج التربوية توفير فرص لهُ أمام الطلبة، وتعلمهم تنية الشعور

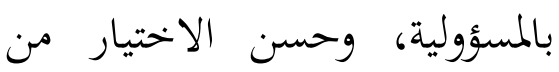
وسط البدائل، وتطوير مهارات الحكم على الأمور، والاهتمام بمسألة إنضاج الصغار للمشاركة المبكرة في إعمال الكبار.
• (1) (أن تعمل المنهج التربوية على تخليص المتعلمين من سلوكات سلبية. (1) (1) أن تركز المنهج التربوية على قضية اللغة وتعليمها إلى الطلبة على اختلاف مستوياتمم الدراسية بحيث تصبح اللغة أداة تربية ونماء لشخصياتم، وأن تكون اللغة أداة للتفكير، وأداة للإبداع، وأداة للنمو وان تلحون النعة ادهم الذهني، وأداة لتحليل الخطاب.

\section{ج. عناصر تصميم المنهج} من عناصر تطوير المنهج يمتوي على الأهداف، والمادة، والطريقة، وتنظيم المنهج، والتقويم.

$$
\begin{aligned}
& \text { ( ) (أهداف المنهج } \\
& \text { Y) } \\
& \text { (1) (1) إنظيم المنهج } \\
& \text { ع) طريقة التعليم } \\
& \text { 0) التقييم }
\end{aligned}
$$

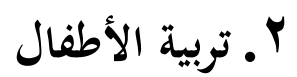


لقـد كانت مسألة العمـر مـن المسـائل

الهامة والجحدلية فيما يتعلق بتعلم اللغة الثانية.

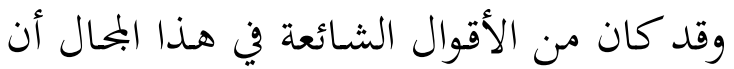

الطفل أقدر مـ البالغ على تعلم اللغة الثانية على أساس عدة افتراضات :

() عقل الطفل أكثر استعدادا من ناحية

بيولجية، فهو أطوع وأكثر مرونة.

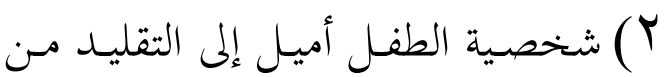

شخصية البالغ بشكل عام.

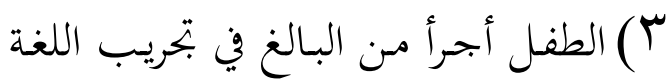

الثانية وعدم الحرج من الأخطأ اللغوية.

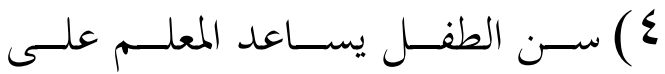

استخدام أساليب تعليمية أكثر تنويعا

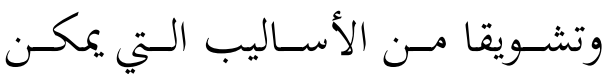

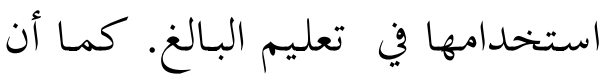

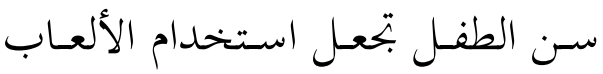

اللغوية والغناء أليق من استخدامها في الئي

$$
\text { تعليم البالغ. }
$$

أ) طريقة تعليم اللغة العربية للأطفال
كمـــا أن تعلـيم اللغــات الأجنبيـة،

فالهدف الأول في تعليم اللغة العربية للأطفال

في روضة الأطفال هو لتعريف العربية في سن

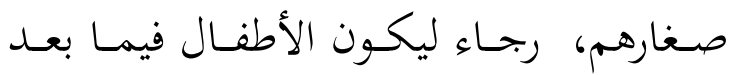
محبين ومرغبين في تعلم العربية. ولذلك يرجى من قبل المدرسين أن يملكوا قدرة خحاصة عميقة في تنفيذ عملية التعليم والتعاليم للحصول على ني ذلك الهدف المرجو. ولاسيما عن طريقة تعليم اللغة الأجنبية وخاصة العربية للأطفال.

إن للمـــدرس دور كبـير في اختيــار

وتعيين الطريقة المناسبة للتعليم. وعلى المدرس

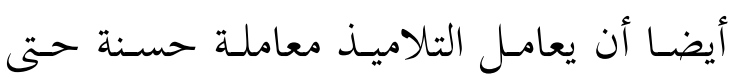
يكونوا فرحين في فصل للدراسة. فعلى مدرس

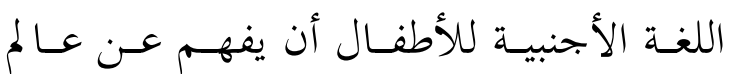
الأطفــال فهمــا صـحيحا. وأن يفهــم عـن الألعاب التي يمبها الأطفال، وعن الشخصية التي يقلدوغا وغير ذلك. \بمعرفة عالم الأطفال

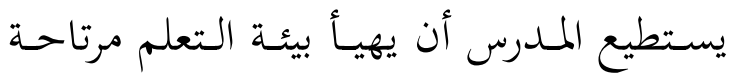
للأطفال ولا يشعرون بأفهم غرباء في تعلم اللغة

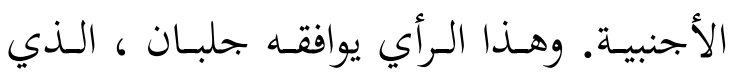

\section{${ }^{7}$ Yulani Nurani Sujiono, Konsep Dasar}

Pendidikan Anak Usia Dini, Jakarta: Indeks, 2011, hlm 145 
يرى بأن اللغة يجدر أن يتعلم في بيئة طيبة وأن

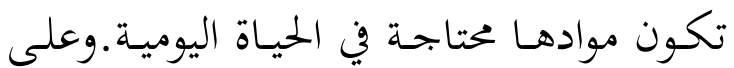
المـــرس أن لا يـترجم الكلمــات إلى اللغـــة

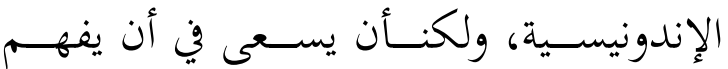
الأطفال عن الكلمـات باستخدام الإشـارات وحركات الجسم، واستخدام دمية أو أي طريقة أخرى التي تساعد المدرس في إفهام معاني الكلمـات للأطفـال سويانطوا نذكر فيما يلي بعض الطرق التي يمكن أن يقوم بها المدرس في

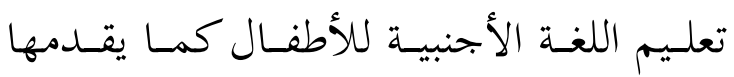

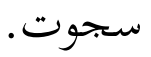

\section{ب) المنهج الدراسي لروضة الأطفال}

مـن مبـادئ العامـة في التعليم هي أن كـتم عمليـة التعلـيم كثيرا بطبع التلاميـذ مـن

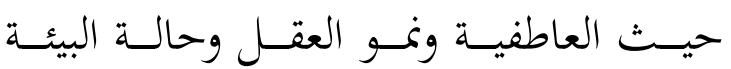
الاجتماعي والثقافي تحولم. إن روضة الأطفال نــوع مــن مؤسســة التربيـة الرسميسة لصــار

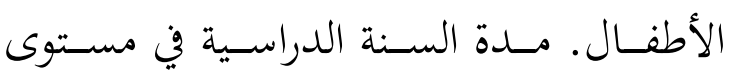
روضة الأطفال سنتين. والمنهج الدراسي روضة الأطفــال يتكــون مـن عـدة برنـامج التعلــيم والتنظيم عـن كفــاءة المثبتــة وطريقـة حصـولها وتطبيقها تتناسب بقدرة كل منطقة. ذلك هو
التعريف المـذكور في المـنهج الدراسي المؤسسس على الكفـاءة لروضـة الأطفـال ؟ . . ب. وأمـا

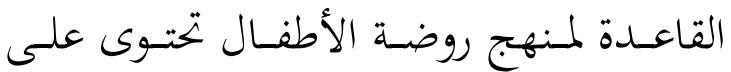
بحـالين تطويرين: (1) ممارسـة تطـوير عمليـة الدراسة، (r) وتطويرا لكفاءة الأساسية. "َ. تعليم اللغة العربية على أساس التربية

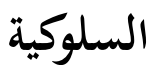
تقـول النظريـة السـلوكيةأن اكتسـاب الأطفال للغة والمحادثة والفهم جاء مـن خارج نفسس الأطفـال، أعني مـن البيئة التي تحولهم. يـرى أهـل هـذه النظريـة أن الأطفـال هـو قابـل سـلبي مسن بيئتهم، ولـيس لـه دور إيبـابي في عملية تطوير لغتهم. وأن عملية تطوير اللغة

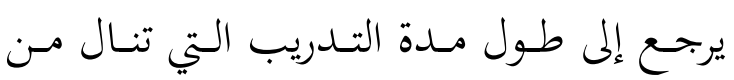
$\wedge$ بيئتهم.

رفضت النظرية السلكية بأن للأطفال قاعـدة لغوية وقدرة لتجريد خصائص المهمة ^عبد العزيز بن إبراهـيم العصيلي، النظريات اللغوية والنفسية وتعليم اللغة العربية، الرياض: جامعة الإمام محمد بن سعود الإسلامية، YIص $ص 1999$ 
مـن اللغـة. واتفقـوا على أن فتيج البيئة المعينـة تقوى قدرة تطور لغة الأطفال. هذا الرأي فيما بعــد مشــهور بطريقـة "المثـــر و الاسـتجابة" (Stimulus Respon) المهـارات هـو عبـارة عـن تكـوين ثنائيـة مثير استجابة التى تصبح أقوى مع التعزيز • وعند تطبيق هذه النظرية على تعلم اللغة سنجد أن هناك مواقف معينة تستدعى استجابة معينة، فمقابلـة أحسـ الأشـخاص تسـتدعى نـوع مـن التحيـة، وسـتنال الاسـتجابة تعزيـزا إذا حصـل الناتج المرغوب، أي إذاكانت التحية مفهومة. أمـا في حالـة فشـل الاتصـال فـإن الاسـتجابة النابتهة لن تنـال تعزيزا وسـيتخلى المتعلم عنها لصـالح استتجابة أخــى يؤمـل بناحسه ومسن ثم تعزيزها.

أ) التعلم على أساس التربية

\section{السلوكية}

السلوك هو أيّ نشاط (جسمي، أو

عقلي، أو اجتماعي، أو انفعالي) يصدر من

9ترجمة عيسى بن عودة الشريفي، نظريات

تعلم اللغة الثانية، الرياض: مطبع جامعة الملك

سعود،
الطفل نتيجة لعلاقة دينامية، وتفاعل بينه وبين البيئة المحيطة به، والسلوك عبارة عن استجابة أو استجبات لمثيرات معينة. 'لوهو خاصية أولية من خصائص الطفل. فدراسة خصائص طفل هذه المرحلة يساعد في تنمية قدرته وتوجيه سلوكه. ومن جهة أخرى أن السلوك هو توقعات الفرد عن شيئ بميل السلوكية وهذا الميل مطابقا بتلك التوقعات. 'I التربية السلوكية هي عملية التربوية بتطوير قيام السلوكي نهو المتعلم حتى يكون هذا القيام سلوكا في نفس المتعلم ويقدر أن يطابق المتعلم قيامه في المحتمع كالإنسان الديني وحب الوطن والخالاقة والمنتجة. ومن قول الإدارة التعليمية والثقافة السنة · ل • ب الأية أ تقول أن التربية السلوكية الجيد لا يكفي بعملية المعرفي الجيد ولاكن لابد فيها أن يكون الذوق والخلوق الجيد أيضا.

$$
\begin{aligned}
& \text { •'المرجع السابق، مصطفى عبد السميع محمد، } \\
& \text { مهارات الاتصال والثغاعل في عملية التعليم والتعلم، }
\end{aligned}
$$

${ }^{11}$ Op.cit, Yunus Abidin, Pembelajaran Bahasa Berbasis Pendidikan Karakter, hlm 53 
ب)حقائق العملية حول التربية

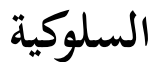

\section{( ) (1) تصميم التربية السلوكية}

إن اللغة هي وسيلة الاتصال في الحياة

فعملية اللغوية من عملية اليومية، وهذه العملية

تقع في كل وقت من حياة الناس. نستطيع أن

نعرف كيفية الإنسان من استخدام لغته.

وباللغة فيه العملية في ترقية الثقافة، تنمية

الحضارة، وتغيير البيئة في حياة الإنسان

وحفظها.

(Y مبادئ تطوير التعيلم على

أساس التربية السلوكية

مبادئ تطوير التعيلم على أساس التربية

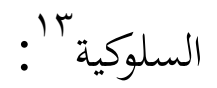

$$
\text { الاستمراري }
$$

(ب) من ملال جميع المواد

المدروسة، و والنمو النفسية،

وثقافة أحد الموحدة التربوية

${ }^{12}$ Op.cit, Yunus Abidin, Pembelajaran

Bahasa Berbasis Pendidikan Karakter, hlm 46

${ }^{13}$ Op.cit,Zubaedi, Desain Pendidikan

Karakter Konsepsinya dan Aplikasinya dalam

Lembaga Pendidikan,hlm 138
في جميع عوامل التربوية بالمنهج

$$
\text { الدراسية كان أو خارجه }
$$

أنّ قيمة السلوكية لا يُعلم

$$
\text { ولاكن يُطور بعملية التربوية }
$$

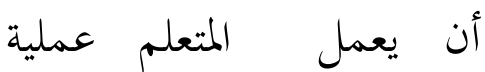

$$
\text { التربوية بالنشاط والجذابة }
$$
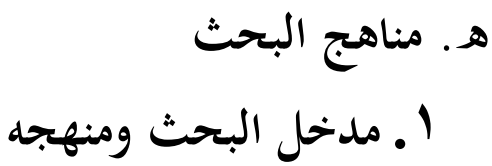

تستخدم الباحثة في هذا البحث منهج

البحث التطويري (D \& R)وهي طريقة البحث

المستخدمة للحصول على نتاج معين وبتربية

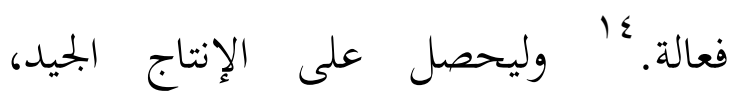

تستخدم الباحثة تحليل الحاجات قبل عملية

التصميم. وتصمم الباحثة منهج تعليم اللغة

العربية ثم تطوره في مجال التربية لترقية فعالية تعلم اللغة العربية في روضة الأطفال. والنتائج التى ستطورها الباحثة من تصميم هذا المنهج يشمل على عملية الطلبة في روضة الأطفال ويشتمل أيضا على عناصر المنهج الأربعة، هي

${ }^{14}$ Sugiyono, Metode Penelitian Kuantitaif, Kualitatif, dan R \& D, (Bandung: Alfabeta, 2009), hlm 297 


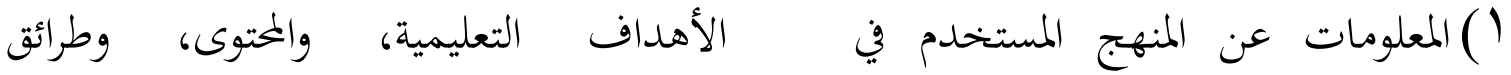
التدريس6 والتقويم. المدرسة.

إجراءات تصميم منهج تعليم

(أ)

اللغة العربية على أساس التربية

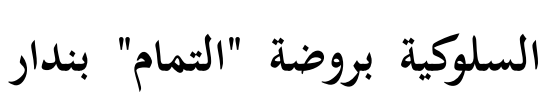

\section{لالامفونج}

المعلومات عن المنئج المستخدم Y) المعلومات عن عملية تعليم وتعلم اللغة العربية في روضة الأطفال.

ب) الإقتراحات والتعليقات والمدخلات العامة حول محتوى المنهج المصمم.

تستخدم الباحثة مزيج من إجراتين

للبحث التطويري وتصميم المنهج في قيام هذا البحث بتغيّر وتعديل على حساب الحاجة

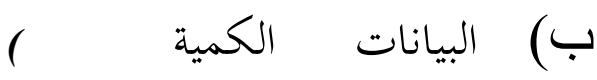

\section{Quantitative Data)}

وتقدير فيه. وترك الباحثة الخطة الثامنة وتشتمل هذه البيانات على :

( ) الموضوعات والمواقف التى يحتاج إليها

والتاسعة من نموذج بور وغال لإنقاذ الوقت

ويرغب فيها التلاميذ والتى تعرف من

وتكتفي بتلك الخطوات السابع، وترك كذلك

$$
\text { نتائج الاستبانة. }
$$

الخطة العاشرة في نفس النموذج لأن هذا

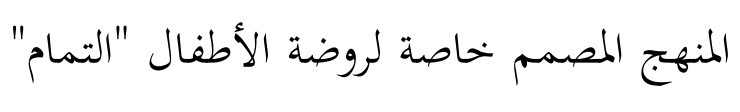
بندار لامفونج.

$$
\text { ا ـ البيانات والمعلومات }
$$

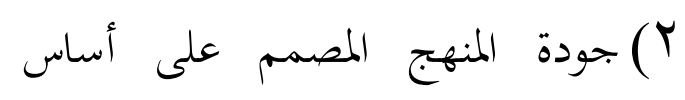
التربية السلوكية لتعليم اللغة العربية في

$$
\text { روضة الأطفال ومالئمته للتطبيق. }
$$

ب) نتائج الاستبانة عن إمكان تطبيق هذا

البيانات ومصادرها في هذا البحث

$$
\text { تتكن من : }
$$

المنهج في روضة الأطفال التمام بندار

$$
\text { •الامفونج }
$$

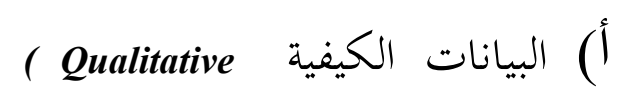

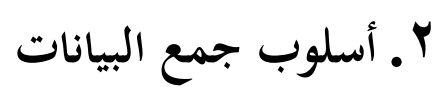

\section{Data)}

$$
\text { تشتمل هذه البيانات على : }
$$


تستخدم الباحثة أسلوب البحث:

الملاحظة (Observation )، المقابلة )

(Interview)

$$
\begin{aligned}
& \text { f } \\
& \text { n بموعة أقصى النتائج لموضوع } \\
& = \\
& \text { واحد }
\end{aligned}
$$

( ) (أسلوب تحليل المضمون Content ) ( ) Analysis)

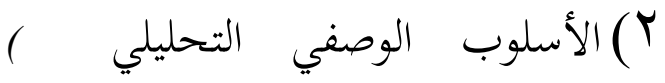
Descriptive Analysis)

\section{ب) بحليل البيانات الكمية}

لتحليل البيانات الكمية من نتائج

الاستبانة المقيدة التى يقومها المستجيبون

بقائمة التدقيق (checklist)، وتستخدم الباحثة

فيه التحليل الإحصائي الوصفي Descriptive Statistic Analysis)

تفتش الباحثة نتائج الاستبانة

لكل موضوع باستخدام الرمز 10 :

P
l

${ }^{15}$ Nana Sudjana, Penelitian Hasil Proses

Belajar Mengajar, (Bandung: Rosda, 2006), hlm 131 
التلاميذ، ع ) تصميم منهج تعليم اللغة العربية على أساس التربية السلوكية بمراعاة حاجات المدرسة والتلاميذ ومستوى قدرقم، 0 0) التحكيم من الخبراء في بحال تعليم اللغة العربية على المنهج المصمهم، ج) تصحيح المنهج مناسبا بنتائج التحكيم من الخبراء، V Vحربة منهج تعليم اللغة العربية الذي تم تصميمه على أساس التربية السلوكية في روضة الأطفال "التمام" بندار لامفونج، م) تصحيح المنهج على أساس التربية السلوكية المعد مناسبا بالتعليقات والمداخحلات من المدرسات. Y. ينتج المنهج التعليمية على أساس التربية السلوكية في روضة الأطفال التمام بندار لامفونج من هذا البحث بمواصفاته الآتية :المنتج في هذا البحث هو منهج تعليم: اللغة العربية، هذا المنهج مكتوب في عدد من الصفحات الورقية، يتكون هذا المنهج المكتوب من :الإطار العام، ذاتية روضة

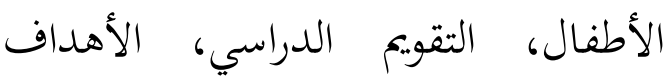
العامة والأهداف الخاصة في تعليم اللغة العربية، الأنشطة التعليمية، طرق التعليم
المستخدمة، المقرر الدراسي لتعليم اللغة

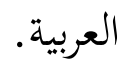

". لمدى صلاحية هذا المنهج المصمم،تقوم بأربعة الخطوات على موافقة الاستخدام والتطبيق لمنهج تعليم اللغة العربية على أساس التربية السلوكية من الخبراءورئيس المؤسسة ورئيسة ومُلدرسة روضة الأطفال

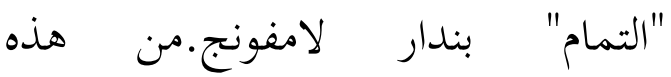
الخطوات، تخلص الباحثة بنتيجتين :

() يتضح من الجدول لنتيـجة

الخبراء أن مضمون المنهج المطور على أساس التربية السلوكية كله يصل إلى

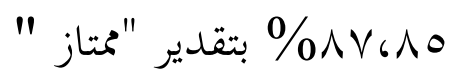
Y) نتيجة موافقة الاسيتخدام والتطبيق لمنهج تعليم اللغة العربية على أساس التربية السلوكية من رئيس المؤسسة ورئيسة ومُل وربة

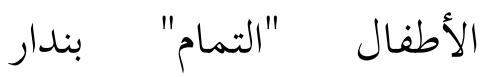
لامفونج بلدرجة النجاح 


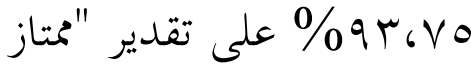

11

أ. التوصيات والاقتراحات

بعد ما انتهينا من هذه الدراسة، تريد

الباحثة تقديم بعض الاقتراحاتما يلي :

ا ـ يرجى أن تكون نتائج البحث تفيد من

يحب ويهتم بالعربية وتعليمهائي المدارس

أوالجامعات ولاسيما مدرسو العربية في

روضة الأطفال.

r. يرجى تطبيق هذا المنهج في تعليم العربية

وجعلها مصدرا لتطوير المنهج الدراسي.

r. يرجى هذا البحث أن يكون مرجعا من

المراجع في البحث لمن يقوم بالبحوث

العلمية بعدها. ويرجى أيضا أن تقام

بكوث أخرى بمثل هذا البحث بأسئلة

أوسع، كتطوير مادة التعليم أو وسائل

تعليم العربية في روضة الأطفال.

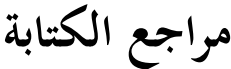

إبراهيم بسوني عميرة. المنهج وعناصره، القاهرة:

دار المعارف، 1991
عبد الجحيد طعمة، حلبي. التربية الإسلامية

لأولاد منهجا وهدفا وألوبا. بيروت سوت

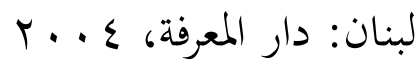

ترجمة عيسى بن عودة الشريفي.نظريات تعلم

اللغة الثانية، الرياض: مطبع جامعة

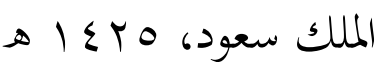

ذوقان عبيدات وآخرون.البحث العلمي -

مغهومه أداته واماليبه-، الرياض: دار

أسامة للنشر والتوزيع، 99 V

حمد محمود الخوالدة.أسس بناء المناهج التربوية

وتصميم الكتاب التعليمي، عمان: دار

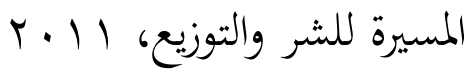

رجاء وحيد دويدري.البحث العلمي أساسياته

النظرية وممارسته العملية، دمشق -

سورية، دار الفكر : م . . ب

رشدي أحمد طعيمةتتعليم العربية لغير الناطقين

كما مناهجه وعناصره، منشورات المنظمة

الإسلامية للتربية والعلوم والثقافة-

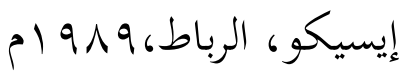

Abdullah

Idi. PengembanganKurikulumTeoridanP 
raktek, Yogyakarta: Arruz Media,2007

Agus Wibowo. Pendidikan Karakter Usia Dini. Yogyakarta: Pustaka Pelajar, 2012

Dakir. Perencanaan dan Pengembangan Kurikulum, Jakarta: Rineka Cipta, 2004

Moh. Ainin. Metodologi Penelitian Bahasa Arab, Surabaya: Hilal Pustaka, 2010

Oemar Hamalik. Manajemen Pengembangan Kurikulum.

Bandung: Rosda, 2007

Nusa Putra. Research \& Development Penelitian dan Pengembangan:
Suatu Pengantar. Jakarta: Rajawali Press, 2012

Rusman. Manajemen Kurikulum, Jakarta: Rajawali Press, 2009

Sugiyono. Metode Penelitian Kuantitaif, Kualitatif, dan $R$ \& $D$, Bandung: Alfabeta, 2009

Yulani Nurani Sujiono, Konsep Dasar Pendidikan Anak Usia Dini, Jakarta: Indeks, 2011

Yunus Abidin, Pembelajaran Bahasa Berbasis Pendidikan Karakter, Bandung: Refika Aditama, 2012

Zubaedi, Desain Pendidikan Karakter Konsepsinya dan Aplikasinya dalam Lembaga Pendidikan, Jakarta: Kencana, 2011 